\title{
Effectiveness of Acute Care Remote Triage Systems: a Systematic Review
}

\author{
Joel C. Boggan, MD, MPH ${ }^{1,2}$, John Paul Shoup, MD ${ }^{3}$, John D. Whited, MD2,4, \\ Elizabeth Van Voorhees, $P h D^{1,5}$, Adelaide M. Gordon, $M P H^{4}$, Sharron Rushton, DNP', \\ Allison A. Lewinski, $P h D^{4}$, Amir A. Tabriz, $M D, P h D^{7}$, Soheir Adam, $M D^{8}$, \\ Jessica Fulton, PhD ${ }^{1,5}$, Andrzej S. Kosinski, PhD ${ }^{9,10}$, Megan G. Van Noord, MSIS ${ }^{17}$, \\ John W. Williams Jr, MD ${ }^{2,4}$, Karen M. Goldstein, MD ${ }^{2,4}$, and Jennifer M. Gierisch, PhD 2, 12
}

\begin{abstract}
${ }^{1}$ Hospital Medicine Team ( $\left.111 \mathrm{M}\right)$, Durham Veterans Affairs Health Care System, Durham, NC, USA; ${ }^{2}$ Division of General Internal Medicine, Department of Medicine, Duke University School of Medicine, Durham, NC, USA; ${ }^{3} B J C$ Medical Group, St. Louis, MO, USA; ${ }^{4}$ Center of Innovation to Accelerate Discovery and Practice Transformation, Durham Veterans Affairs Medical Center, Durham, NC, USA; ${ }^{5}$ Department of Psychiatry and Behavioral Sciences, Duke University School of Medicine, Durham, NC, USA; ${ }^{6}$ School of Nursing, Duke University, Durham, NC, USA; ${ }^{7}$ Division of Pharmaceutical Outcomes and Policy, UNC Eshelman School of Pharmacy University of North Carolina at Chapel Hill, Chapel Hill, NC, USA; ${ }^{8}$ Department of Medicine, Division of Hematology, Duke University, Durham, NC, USA; ${ }^{9}$ Department of Biostatistics and Bioinformatics, Duke University Medical Center, Durham, NC, USA; ${ }^{10}$ Duke Clinical Research Institute, Durham, NC, USA; ${ }^{11}$ University of California at Davis, Davis, CA, USA; ${ }^{12}$ Department of Population Health Sciences, Duke University School of Medicine, Durham, NC, USA.
\end{abstract}

BACKGROUND: Technology-based systems can facilitate remote decision-making to triage patients to the appropriate level of care. Despite technologic advances, the effects of implementation of these systems on patient and utilization outcomes are unclear. We evaluated the effects of remote triage systems on healthcare utilization, case resolution, and patient safety outcomes.

METHODS: English-language searches of MEDLINE (via PubMed), EMBASE, and CINAHL were performed from inception until July 2018. Randomized and nonrandomized comparative studies of remote triage services that reported healthcare utilization, case resolution, and patient safety outcomes were included. Two reviewers assessed study and intervention characteristics independently for study quality, strength of evidence, and risk of bias.

RESULTS: The literature search identified 5026 articles, of which eight met eligibility criteria. Five randomized, two controlled before-and-after, and one interrupted time series study assessed 3 categories of remote triage services: mode of delivery, triage professional type, and system organizational level. No study evaluated any other delivery mode other than telephone and in-person. Meta-analyses were unable to be performed because of study design and outcome heterogeneity; therefore, we narratively synthesized data. Overall, most studies did not demonstrate a decrease in primary care (PC) or emergency department (ED) utilization, with some studies showing a significant increase. Evidence suggested local, practice-based triage systems have greater case resolution and refer fewer patients to $\mathrm{PC}$ or $\mathrm{ED}$ services than regional/national

Prior Presentations This work has not been presented previously at any conference.

Electronic supplementary material The online version of this article (https://doi.org/10.1007/s11606-019-05585-4) contains supplementary material, which is available to authorized users.

Received November 14, 2019

Revised November 14, 2019

Accepted November 25, 2019

Published online January 2, 2020 systems. No study identified statistically significant differences in safety outcomes.

CONCLUSION: Our review found limited evidence that remote triage reduces the burden of $\mathrm{PC}$ or $\mathrm{ED}$ utilization. However, remote triage by telephone can produce a high rate of call resolution and appears to be safe. Further study of other remote triage modalities is needed to realize the promise of remote triage services in optimizing healthcare outcomes.

PROTOCOL REGISTRATION: This study was registered and followed a published protocol (PROSPERO: CRD42019112262).

KEY WORDS: remote triage; telephone triage; healthcare utilization; patient safety; systematic review.

J Gen Intern Med 35(7):2136-45

DOI: $10.1007 / \mathrm{s} 11606-019-05585-4$

(C) Society of General Internal Medicine (This is a U.S. government work and not under copyright protection in the U.S.; foreign copyright protection may apply) 2019

\section{INTRODUCTION}

The US health care system currently faces several challenges, including caring for an increasing elderly population, ${ }^{1}$ patients with multimorbidity, ${ }^{2,3}$ and uneven geographic distributions of primary care providers (PCPs). ${ }^{4}$ Busy PCP appointment schedules compound these issues, making it challenging to access acute and chronic care within many primary care (PC) settings. ${ }^{5}$ Many patients experience additional access barriers, ${ }^{6}$ including poor internet access and insufficient public transportation. ${ }^{7}$ Such challenges push patients to seek acute and chronic care outside the PC setting. ${ }^{8}$ A recent study reported $12 \%$ of patients visited emergency departments (ED) due to care needed outside of their PCP office hours and another $7 \%$ of patients for an inability to visit another 
provider. ${ }^{9}$ Unsurprisingly, patients with after-hours PCP availability have lower rates of higher level care utilization. ${ }^{10}$

One method of triaging patients to the appropriate level of care is through technology-based systems that facilitate remote decision-making, defined as making clinical decisions in the absence of face-to-face encounters. Thus, remote triage can be delivered in synchronous or asynchronous formats via platforms such as telephone, email, or video conferencing to address barriers to access. ${ }^{11-14}$ Authors of a 2004 Cochrane systematic review ${ }^{15}$ determined telephone triage consultation decreased urgent after-hours general practitioner (GP) patient visits, although it remains unknown if this represents an absolute decrease in utilization or care deferral to a later time. A more recent systematic review found limited information to assess clinical outcomes of remote triage, with mixed results on ED utilization. ${ }^{16}$ Another recent review determined additional information is needed for outcomes of telephone-only triage. ${ }^{17}$ Given persistent uncertainty around clinical and utilization outcomes after accessing acute care remote triage services, we conducted a systematic review to examine outcomes across various triage modalities.

\section{METHODS}

\section{Study Design}

This work is part of a Veterans Health Administration (VHA) funded report (www.hsrd.research.va.gov/publications/esp). This review addresses "What are the outcomes of care utilization, case resolution, and patient safety associated with remote triage systems?" We followed a published protocol (PROSPERO: CRD42019112262) and PRISMA (Preferred Reporting Items for Systematic Reviews and Meta-Analyses) guidance. $^{18}$

\section{Data Sources and Searches}

In collaboration with a reference librarian, we searched MEDLINE® (via PubMed®), EMBASE, and CINAHL from inception through July 27, 2018 (Appendix Table 1). We also screened references from high-quality systematic reviews and studies identified by stakeholders during topic development.

\section{Study Selection}

Our prespecified inclusion and exclusion criteria are listed in Appendix Table 2. Major inclusion criteria were comparative evaluation of remote triage services for initial assessment and management of acute, undifferentiated, and unscheduled outpatient general medical clinical issues initiated by patients. We used artificial intelligence (AI) technology (DistillerAI, Evidence Partners Inc., Manotick, ON, Canada) to assist with initial abstract screening. ${ }^{19}$ Abstracts of 100 articles were classified independently for relevance by two senior investigators and used as an AI training set. Articles were assigned a relevance probability by DistillerAI using Naive Bayes and
Support Vector Machine classifiers. All citations with probability of 1 proceeded to full-text review. All lower probability citations were screened by one investigator for progression to full-text review. Citations unclassified by DistillerAI underwent screening by two investigators. Articles included by either investigator or DistillerAI underwent full-text screening by two investigators for inclusion. Disagreements were resolved by consensus between investigators or by a third investigator.

\section{Data Extraction and Quality Assessment}

One investigator abstracted data into a customized DistillerSR database; a second investigator reviewed data for accuracy. Data elements included descriptors of applicability to our review question, study quality, interventions, and outcomes. Multiple reports from a single study were treated as one study. Two investigators independently assessed study quality using the Cochrane Effective Practice and Organisation of Care (EPOC) Risk of Bias (ROB) Tool. ${ }^{20}$ We assigned summary ROB scores (low, unclear, or high) to individual studies.

\section{Data Synthesis and Analysis}

After summarizing study characteristics (Appendix Table 3), we determined feasibility of completing quantitative synthesis (i.e., meta-analysis) to estimate summary effects. We were unable to aggregate outcomes because of study design and outcome heterogeneity; therefore, we narratively analyzed data. In narrative synthesis, we prioritized evidence from higher quality studies (e.g., randomized designs, low ROB) and focused on identifying patterns in results across outcomes. We categorized studies by type of remote triage comparison: mode of triage delivery (i.e., telephone, in-person), triage professional type (e.g., nonclinical call handler, nurse, GP), and organizational level (e.g., national triage systems, local in-practice triage systems). When possible, we present forest plots of point estimates and $95 \%$ confidence intervals of individual studies.

\section{Role of the Funding Source}

The US Department of Veterans Affairs was not involved in the design, conduct, or analysis interpretation.

\section{RESULTS}

From 5026 screened citations, we reviewed 100 full-text articles and identified 8 unique eligible studies ( 1 individual randomized clinical trial (RCT), 4 cluster RCTs, 2 controlled before-after studies, and 1 interrupted time series study) (Appendix Fig. 1). All studies were conducted in Europe.

\section{Intervention Characteristics}

Details of included studies are in Appendix Table 3 and Appendix Table $4 .^{21-28}$ Studies assessed the effects of remote triage on health care utilization $(n=8),{ }^{21-28}$ case resolution 
$(n=4), 23,24,26,27$ and patient safety $(n=2){ }^{21,} 26$ In four studies, the unit of enrollment was patients; ${ }^{23-25,27}$ in three, it was incoming phone calls; ${ }^{22,26,28}$ and in one, it was afterhours periods for involved practices. ${ }^{21}$ We were able to calculate mean differences (MDs) and risk ratios (RRs) for seven studies. $^{21-27}$

\section{Effects on Health Care Utilization}

Health care utilization was the most commonly reported metric (eight studies, Table $1 .^{21-28}$ Seven studies (four randomized, three nonrandomized) measured utilization as PC visits, ${ }^{21-25,27,28}$ while seven (four randomized, three nonrandomized) measured ED utilization. ${ }^{21-26,28}$
Studies assessing subsequent PC utilization after remote triage compared telephone triage to in-person visits $(n=$ $3),{ }^{21}, 24,25$ as well as calls managed by different triage professional types $(n=1)^{22}$ and at different levels of triage organization $(n=3$, Fig. 1$){ }^{23,} 27,28$ Only one study, ${ }^{28}$ a controlled before-after study rated high ROB, demonstrated a reduction in utilization of $\mathrm{PC}$ services attributable to the tested telephone triage system. Four studies reported statistically significant increases in PC utilization with telephone triage, ${ }^{21}, 22,24,25$ while three showed nonsignificant effects. ${ }^{22,23,27}$ One study reported insufficient information to calculate a point estimate. $\left.{ }^{28}\right]->$

Table 1 Summary of Utilization Outcomes in Remote Triage Studies

\begin{tabular}{ll}
\hline \hline Study design & Comparison \\
\hline $\begin{array}{l}\text { Randomized } \\
\text { McKinstry, 2002 }\end{array}$ & \\
Individual-randomized & Face-to-face consultation $(N=188)$ \\
& vs telephone advice $(N=182)$ \\
& \\
Campbell, 2014 & \\
Cluster-randomized & GP triage $(N=5171)$ vs nurse triage \\
& $(N=5648)$ vs usual care $(N=5572)$
\end{tabular}

Richards, $2004^{23}$

Cluster-randomized

Cragg, $1997^{27}$

Cluster-randomized

Lattimer, $1998^{26}$

Cluster-randomized

Nonrandomized

Turner, $2013^{22}$

Controlled before-after

Munro, $2000^{28}$

Controlled before-after

Richards, $2002^{24}$

Interrupted time-series
Nurse triage (NHS Direct* $N=2260$ ) vs usual practice $(N=2458)$

Commercial deputized physician $(N=1082)$ vs longitudinal general practice physicians $(N=1037)$

Nurse triage $(N=7184)$ vs usual practice $(N=7308)$

Total number of NHS 111 calls $N=408,851$

Total number of NHS Direct calls $N=68,500$

Nurse triage $(N=3452)$ vs usual practice $(N=1233)$

\section{Results}

Number of subsequent primary care contacts, mean (SD)

- $0.4(0.7)$ vs $0.6(0.8)$; difference $-0.2(95 \% \mathrm{CI}-0.3$ to 0.0$)$ Number of subsequent emergency department contacts, mean $(\mathrm{SD}) \mathrm{N}$

- $0.0(0.1)$ vs $0.0(0.2)$; difference $0.0(95 \% \mathrm{CI}-0.1$ to 0.0$)$

Primary care contacts after index over 28-day follow-up

period, mean $(\mathrm{SD})$

- GP: $2.62(2.62)$

- Nurse: $2.78(1.5)$

- Usual care: $1.87(1.3)$

Emergency department contacts after index over 28-day

follow-up period, mean (SD)

- GP:0.03 (0.19)

- Nurse triage: $0.03(0.22)$

- Usual care: $0.03(0.21)$

Mean number of practice consultation consultations per patient $(95 \% \mathrm{CI})$

- 1.43 vs 1.37; Poisson regression ${ }^{\dagger}, 1.04$ (0.94 to 1.15 )

Mean number of after-hours consultation per patient

- 0.082 vs 0.077; Poisson regression ${ }^{\dagger}, 1.05$ (0.72 to 1.52)

Mean number of ED consultations per patient

- 0.053 vs 0.047 ; Poisson regression ${ }^{\dagger}, 1.10$ (0.79 to 1.54$)$

Use of primary care in 2 weeks after call; percent, $(95 \% \mathrm{CI})$

- Practice doctors: 46.5 (42.1 to 50.6) vs deputizing doctors:

44.2 (40.2 to 48.3 ); $p=0.299$

Attendance at ED unit within 3 days of call:

- 412 (95\% CI 374 to 452 ) vs $391^{*}$ (equivalence

limits 313 to 489 )

Monthly ED attendances after implementation of NHS 111; percent change, $(95 \% \mathrm{CI})$

- $-0.1(-3.8$ to 3.7$)$

Percent change in monthly primary care utilization with NHS

111

- 2.5 ( -3.5 to 8.5$)$

In 3 NHS Direct areas, the estimated trend changed from $2 \%$ a month before NHS Direct to $-0.8 \%$ afterward (estimated relative change $-2.9 \%$ [95\% CI -4.2 to $-1.5 \%]$ ), whereas in the 6 control cooperatives, the trend hardly changed, from $0.8 \%$ a month before to $0.9 \%$ afterward (relative change $0.1 \%$ [95\% CI -0.9 to $1.1 \%]$ ]

Emergency department visits within 1 month of initial management; mean, $(\mathrm{SD})$

- $0.033(0.19)$ vs. $0.010(0.10)$ mean difference: $0.023(0.16)$

Primary care visits within 1 month of initial management; mean, (SD)

- 1.35 (1.85) vs $1.01(1.4)$ mean difference: 0.34

*NHS Direct is the first generation of a national 24-h nurse-led telephone helpline in England

${ }^{\dagger}$ The value of no effect for a Poisson regression is 1.00

${ }^{*}$ Adjusted for difference in denominator

$C I=$ confidence interval; $E D=$ emergency department; $G P=$ general practitioner; $N H S=$ National Health Service; $S D=$ standard deviation 


\begin{tabular}{|c|c|c|c|c|c|c|c|c|c|c|c|c|}
\hline \multicolumn{13}{|l|}{ PC Utilization } \\
\hline \multirow{3}{*}{$\begin{array}{l}\text { Study, Year } \\
\text { (Intervention, Control) } \\
\text { Campbell } 2014 \\
\text { (GP, UC) }\end{array}$} & \multirow{3}{*}{$\begin{array}{r}\text { Comparison } \\
\text { Mode }\end{array}$} & \multirow{2}{*}{\multicolumn{2}{|c|}{ ROB Randomized }} & \multirow{3}{*}{$\begin{array}{l}\text { Mean } \\
2.62\end{array}$} & \multicolumn{2}{|c|}{ Intervention } & \multicolumn{3}{|r|}{ Control } & \multirow{2}{*}{\multicolumn{3}{|c|}{ MD $[95 \% \mathrm{Cl}]$}} \\
\hline & & & & & SD & $\mathrm{N}$ & Mean & SD & $\mathrm{N}$ & & & \\
\hline & & unclear & yes & & 1.60 & 5171 & 1.87 & 1.30 & 5572 & & - & $0.75[0.69,0.81]$ \\
\hline $\begin{array}{l}\text { Campbell } 2014 \\
\text { (nurse, UC) }\end{array}$ & Mode & unclear & yes & 2.78 & 1.50 & 5468 & 1.87 & 1.30 & 5572 & & - & $0.91[0.86,0.96]$ \\
\hline $\begin{array}{l}\text { McKinstry } 2002 \\
\text { (Telephone Advice, UC) }\end{array}$ & Mode & low & yes & 0.60 & 0.80 & 182 & 0.40 & 0.70 & 188 & - & 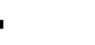 & $0.20[0.05,0.35]$ \\
\hline $\begin{array}{l}\text { Richards } 2002 \\
\text { (Triage, UC) }\end{array}$ & Mode & low & no & 1.35 & 1.85 & 3452 & 1.01 & 1.40 & 1233 & - & 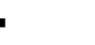 & $0.34[0.24,0.44]$ \\
\hline $\begin{array}{l}\text { Cragg } 1997 \\
\text { (Deputizing GP Practice GP) }\end{array}$ & $\begin{array}{r}\text { Organization } \\
\text { level }\end{array}$ & high & yes & 44.20 & 55.02 & 709 & 46.50 & 58.54 & 680 & + & & $-2.30[-8.28,3.68]$ \\
\hline $\begin{array}{l}\text { Richards } 2004 * \\
\text { (NHS Direct, Practice) }\end{array}$ & $\begin{array}{r}\text { Organization } \\
\text { level }\end{array}$ & low & yes & 1.43 & 2.47 & 2260 & 1.37 & 2.47 & 2458 & 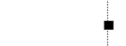 & & $0.06[-0.08,0.20]$ \\
\hline $\begin{array}{l}\text { Richards } 2004^{\dagger} \\
\text { (NHS Direct, Practice) }\end{array}$ & $\begin{array}{r}\text { Organization } \\
\text { level }\end{array}$ & low & yes & 0.08 & 0.52 & 2260 & 0.08 & 0.52 & 2458 & - & & $0.01[-0.02,0.03]$ \\
\hline $\begin{array}{l}\text { Campbell } 2014 \\
\text { (nurse, GP) }\end{array}$ & Professional & unclear & yes & 2.78 & 1.50 & 5468 & 2.62 & 1.60 & 5171 & - & 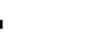 & $0.16[0.10,0.22]$ \\
\hline \multirow[t]{3}{*}{$\begin{array}{l}\text { Turner } 2013 \\
\text { (NHS 111, Before NHS 111) }\end{array}$} & Professional & unclear & no & & & 408851 & & & 408851 & & $\rightarrow$ & $2.50[-3.50,8.50]$ \\
\hline & & & & & & & & & & \multicolumn{2}{|c|}{\begin{tabular}{|c|c|} 
Favors & Favors \\
Intervention \\
Control
\end{tabular}} & \\
\hline & & & & & & & & & & -4.00 & 4.00 & \\
\hline
\end{tabular}

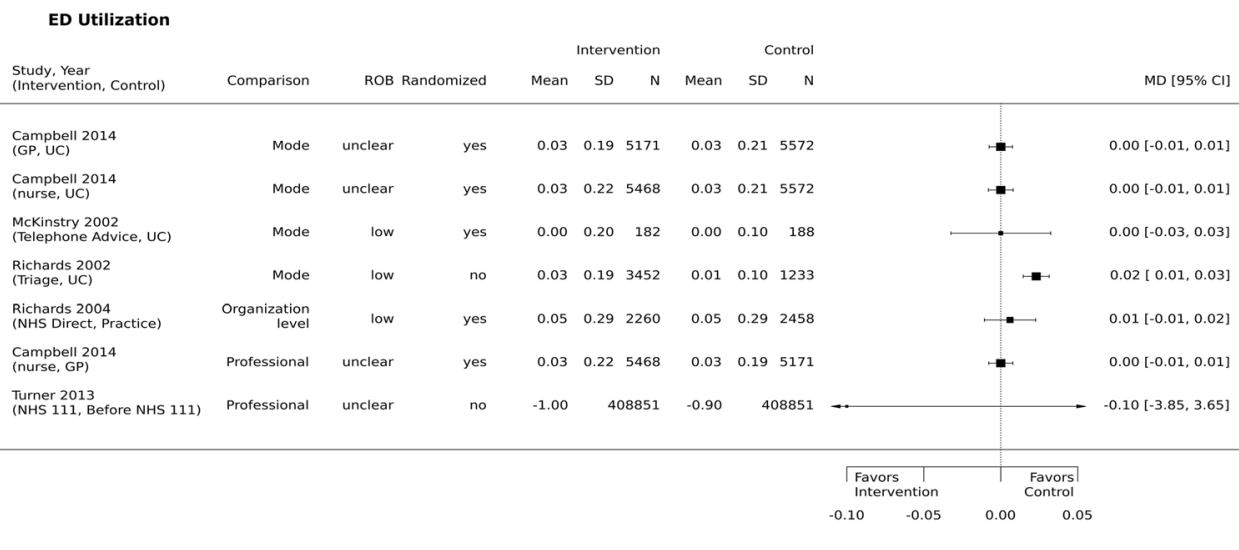

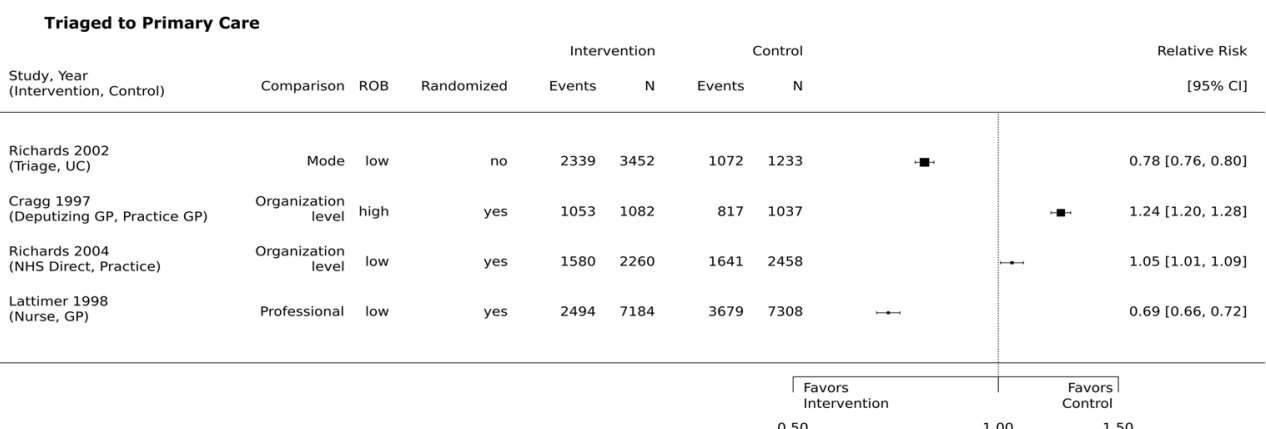

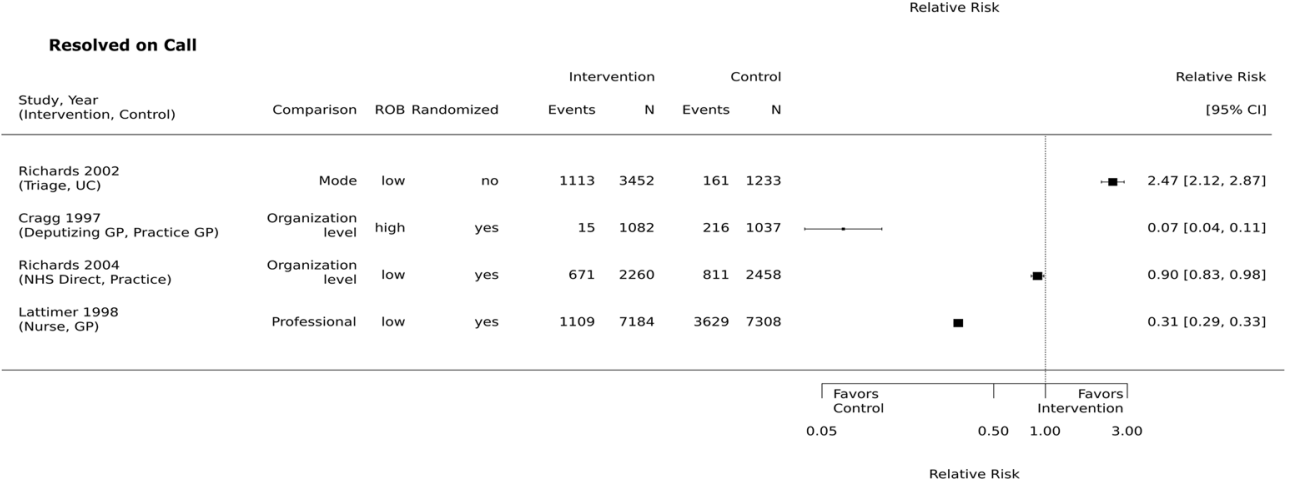

Figure 1 Effects of remote triage on utilization and case resolution outcomes. *Number of primary practice-based care visits within 30 days of index contact. ${ }^{\dagger}$ Number of after-hours visits within 30 days of index contact. $\mathrm{CI}=$ confidence interval; $\mathrm{GP}=$ general practitioner; $\mathrm{ROB}=$ risk of bias; $\mathrm{UC}=$ usual care. 
Studies assessing utilization of ED services compared telephone triage to in-person visits $(n=3),{ }^{21,24,} 25$ management by different triage professional types $(n=2),{ }^{22,26}$ and at different levels of triage organization $\left(n=2\right.$, Fig. 1). ${ }^{23}, 28$ Overall, no study demonstrated a reduction in utilization of ED services attributable to the tested telephone triage system, while one nonrandomized study reported a statistically significant increase. ${ }^{24}$ Two studies were not included in forest plots for methodological reasons. ${ }^{26,28}$

Comparison by Modality. All three studies comparing telephone triage services to in-person practice-based care found an increase in PC utilization with telephone triage over follow-up periods ranging from 14 to 30 days (Fig. 1). ${ }^{21,24,} 25$ A pragmatic, three-arm cluster RCT compared both GP-led telephone triage and nurse-led telephone triage to usual care for patients seeking same-day PC consultations; telephone triage by GPs and nurses was associated with increased PC contacts of $33 \%$ and $48 \%$, respectively, over 28 days. ${ }^{21}$ Another RCT investigated GP-led telephone consultations and found a statistically significant increase in subsequent PC utilization of 0.2 visits in the telephone group within 2 weeks. ${ }^{25}$ Finally, a multiple interrupted time series study assessed nurse telephone triage versus standard management of routine requests for same-day appointments, finding more telephone patients returned for PC within 1 month (MD 0.32, $p<0.001$, for return visits and MD 0.04, $p=0.005$, for afterhours care, Fig. 1). ${ }^{24}$

Neither of two RCTs ${ }^{21,25}$ found a difference in ED utilization between nurse-led and GP-led telephone triage compared with in-person consultation. An additional nonrandomized study $^{24}$ found implementation of telephone triage compared with standard care led to an increase in ED visits postimplementation of telephone triage (MD 0.023, $p<0.001$ ).

Comparison by Professional Type. Two studies assessed effect of triage professional type on PC utilization. ${ }^{21}, 22$ Compared with nurse-led triage, GP-led triage resulted in fewer mean PC contacts within 28 days (MD $-0.16,95 \%$ $\mathrm{CI}-0.10$ to -0.22$).{ }^{21}$ The other study was a controlled beforeafter assessment of an updated National Health Service (NHS) advice line staffed by nonclinical call handlers (NHS 111). ${ }^{22}$ NHS 111 differed from the previous system, NHS Direct, in that nonclinical call handlers applied computerized decision support software with clinician backup to immediately triage incoming calls to appropriate services or offer selfmanagement advice. Compared with NHS Direct, implementation of NHS 111 resulted in an average increase of $2.5 \%$ of 47 monthly PC visits $(95 \%$ CI -3.5 to $8.5 \%$, Fig. 1$)$.

Two randomized ${ }^{21}$ and one nonrandomized ${ }^{22,}{ }^{26}$ studies assessed the effect of triage professional type on utilization of ED services (Fig. 1). The cluster RCT found statistical equivalence between nurse-led triage and GP-led triage for ED use over 3 days. ${ }^{26}$ The cluster RCT comparing GP-led or nurse-led telephone triage with usual care ${ }^{21}$ found no difference in $\mathrm{ED}$ visits over 28 days ( $\mathrm{OR}=0.92,95 \% \mathrm{CI} 0.67$ to
1.26). The study assessing enactment of NHS 111 also identified no change in ED utilization over 1 year. $^{22}$

Comparison by Organization Level. Three additional studies assessed levels of triage organization. ${ }^{23,27,28}$ One cluster RCT compared after-hours care provided by GPs from the patients' own practices to that provided by deputizing services, which are commercial external agencies delegated to cover care for GPs. ${ }^{27}$ This study found no significant differences in number of PC visits over 2 weeks following triage ( 46.5 vs $44.2, p=$ 0.299). Another RCT assessed the relative effects of off-site triage by NHS Direct on consultation workload for PC patients requesting same-day appointments compared with usual onsite nurse telephone triage. ${ }^{23}$ This study reported no differences in patients receiving PC services $(p=0.49)$ or afterhours care $(p=0.81)$ within 1 month (Fig. 1$){ }^{23}$ This study was a controlled before-after design evaluating NHS Direct triage versus GP cooperative telephone triage that reported a small, significant decrease in monthly GP cooperative triage calls after NHS Direct implementation $(-2.9 \%$; $95 \%$ CI -4.2 to $-1.5 \%)^{28}$

Two studies investigated level of triage organization on utilization of ED services (Fig. 1). ${ }^{23,}{ }^{28}$ The study of off-site NHS Direct triage ${ }^{23}$ reported no difference in the number of ED patient visits within 1 month, compared with onsite telephone triage $(p=0.58)$. The controlled before-after study assessing NHS Direct telephone triage also reported no difference after implementation. ${ }^{28}$

\section{Effects on Case Resolution}

Four studies assessed the effects of remote triage on case resolution (Table 2) ${ }^{23,} 24,26,27$ In these studies, people received one of three resolutions: triage to either (1) emergency services or (2) PC services (including urgent care, home, or PC visits immediately or on a future date), or (3) they achieved resolution during initial contact. Three studies were cluster RCTs involving 21,362 patients. ${ }^{23,26,27}$ The fourth was an interrupted time series study of 4685 patients. ${ }^{24}$ One study evaluated modality ${ }^{24}$ one evaluated triage professional type, ${ }^{26}$ and two looked at triage organization level. ${ }^{23,} 27$

Only one study reported the proportion of patients triaged to emergency services ${ }^{27}$ while all studies reported both proportions of patients triaged to additional PC services and achieving immediate resolution. Resolution outcomes were rated high $\mathrm{ROB}$ in one cluster $\mathrm{RCT}^{27}$ and low ROB in two other RCTs and the interrupted time series study. ${ }^{23}, 24,26$

In the study reporting emergency referrals, very few callers were referred directly, representing 14 of 1082 callers $(1.3 \%)$ in the deputized service arm versus 4 of $1037(0.4 \%)$ in the local GP arm. ${ }^{27}$ Appropriateness of referrals was not evaluated.

Cluster RCTs reporting rates of referral to in-person PC services (Fig. 1) 23, 26, 27 found triage interventions referred higher rates of callers to PC services than usual practice 
Table 2 Summary of Case Resolution Outcomes in Remote Triage Studies

\begin{tabular}{|c|c|c|}
\hline Study design & Comparison & Case resolution rate $(\%)$ \\
\hline \multicolumn{3}{|l|}{ Randomized } \\
\hline Cragg, $1997^{27}$ & Commercial deputized physician & Referred to emergency services: \\
\hline \multirow[t]{3}{*}{ Cluster-randomized } & $(n=1082)$ vs longitudinal general & - 14 of $1082(1.3 \%)$ vs 4 of $1037(0.4 \%)$ \\
\hline & practice physicians $(n=1037)$ & $\begin{array}{l}\text { Referred to primary care services: } \\
-1053 \text { of } 1082(97.3 \%) \text { vs } 817 \text { of } 1037(78.8 \%)\end{array}$ \\
\hline & & $\begin{array}{l}\text { Resolved during initial contact without referral: } \\
\text { - } 15 \text { of } 1082(1.4 \%) \text { vs } 216 \text { of } 1037(20.8 \%)\end{array}$ \\
\hline Lattimer, $1998^{26}$ & Nurse triage $(n=7184)$ vs GP triage & Referred to primary care services: \\
\hline \multirow[t]{2}{*}{ Cluster-randomized } & usual practice $(n=7308)$ & $\begin{array}{l}\text { - } 2494 \text { of } 7184(34.7 \%) \text { vs } 3679 \text { of } 7308 \\
(50.3 \%)\end{array}$ \\
\hline & & $\begin{array}{l}\text { Resolved during initial contact without referral: } \\
\text { - } 1109 \text { of } 7184(15.4 \%) \text { vs } 3629 \text { of } 7308 \\
(49.7 \%)\end{array}$ \\
\hline Richards, $2004^{23}$ & Nurse triage (NHS Direct, $n=2260$ ) vs & Referred to primary care services: \\
\hline \multirow[t]{2}{*}{ Cluster-randomized } & usual practice nurse triage $(n=2458)$ & $\begin{array}{l}-1580 \text { of } 2260(69.9 \%) \text { vs } 1641 \text { of } 2458 \\
(66.8 \%) \text {, risk difference } 3.15 \%\end{array}$ \\
\hline & & $\begin{array}{l}\text { Resolved during initial contact without referral: } \\
\text { - } 671 \text { of } 2260(29.7 \%) \text { vs } 811 \text { of } 2458(33.0 \%) \text {; } \\
\text { risk difference }-3.30 \%\end{array}$ \\
\hline \multicolumn{3}{|l|}{ Nonrandomized } \\
\hline Richards, $2002^{24}$ & Nurse triage $(n=3452)$ vs usual & Referred to primary care services: \\
\hline \multirow[t]{2}{*}{ Interrupted time-series } & $\begin{array}{l}\text { practice same-day appointment } \\
\text { assignment }(n=1233)\end{array}$ & $\begin{array}{l}\cdot 2339 \text { of } 3452(67.8 \%) \text { vs } 1072 \text { of } 1233 \\
(86.9 \%)\end{array}$ \\
\hline & & $\begin{array}{l}\text { Resolved during initial contact without referral: } \\
\text { - } 1113 \text { of } 3452(32.2 \%) \text { vs } 161 \text { of } 1233 \\
(13.1 \%) \text {, RR } 2.41(95 \% \text { CI } 2.08 \text { to } 2.80)\end{array}$ \\
\hline
\end{tabular}

$C I=$ confidence interval $; G P=$ general practitioner $; N H S=$ National Health Service; $R R=$ relative risk

coverage in two studies ${ }^{23,27}$ and lower rates in a third, noninferiority study. ${ }^{26}$

All three cluster RCTs reporting rates of call resolution during initial contact (Fig. 1) found local, practice-based services resolved more calls than regional or national triage interventions. $^{23,26,27}$ The interrupted time series study of a triage nurse line found more calls were resolved than the compared practice of maximizing same-day appointments. ${ }^{24}$

Comparison by Modality. The interrupted time series study compared the NHS Direct nurse telephone triage service to a practice standard of assigning patients to same-day GP appointments. ${ }^{24}$ This comparison showed fewer PC appointments scheduled with a triage service (2339 of 3452 callers, $67.8 \%$ ) than accommodating the maximum number of callers within open appointments (1072 of 1233 callers, 86.9\%). NHS Direct also resolved a higher percentage of calls (1113 of 3452 [32.2\%] vs 161 of 1233 [13.1\%], RR $2.41,95 \%$ CI 2.08 to 2.80$).{ }^{24}$

Comparison by Professional Type. A cluster RCT assessing triage-trained nurse-led versus standard practice GP-led afterhours remote triage scheduled 2494 of 7184 (34.7\%) nurse triage callers to PC services, as compared with 3679 of 7308 $(50.3 \%)$ GP triage callers. ${ }^{26}$ This $38 \%$ reduction in the nurseled arm included a $23 \%$ reduction in home visits. However, the nursing arm resolved only 1109 of $7184(15.4 \%)$ calls versus 3629 of 7308 (49.7\%) physician calls. ${ }^{26}$

Comparison by Organization Level. One cluster RCT comparing NHS Direct triage to local practice triage during usual office hours ${ }^{23}$ assigned 1580 of 2260 (69.9\%) NHS Direct callers to same-day PC service versus 1641 of 2458
$(66.7 \%)$ callers in the local arm, a $3.2 \%$ relative increase. The other cluster RCT of after-hours remote triage services using deputized versus practice physicians ${ }^{27}$ found 1053 of 1082 callers $(97.3 \%)$ in the deputized arm were triaged to immediate evaluation as compared to 817 of $1037(78.8 \%)$ callers to the practice arm.

Similarly, the NHS Direct triage service resolved 671 of $2260(29.7 \%)$ calls, while usual practice triage resolved 811 of $2458(33.0 \%)$ calls. ${ }^{23}$ In the other study, the deputized service resolved only 15 of 1082 calls (1.4\%) versus 216 of 1037 $(20.8 \%)$ in the practice physician arm. ${ }^{27}$

\section{Effects on Patient Safety}

Two cluster RCTs addressed the effects of remote triage on patient safety (Table 3). ${ }^{21,}{ }^{26}$ One trial rated unclear ROB evaluated safety as a secondary outcome for patients requesting same-day appointments, ${ }^{21}$ while the other rated low ROB reported safety events as a primary outcome during randomized after-hours periods. ${ }^{26}$ Both trials included ED visitation, hospitalization, and death as safety outcomes and showed no difference in safety outcomes between nurse triage and GP-led usual care. ${ }^{21,26}$

Patient Deaths. The three-arm trial examining safety as a secondary outcome had eight total deaths reported during 7-day follow-up (GP triage $n=5,0.7 \%$, nurse triage $n=2,0.3 \%$, and usual care $n=1,0.1 \%)^{21}$ (Fig. 2). ${ }^{21}$ The other, an equivalence trial comparing patients receiving usual GP telephone management with phone-based nurse triage, found no difference in death within 7 days between the control group $(n=66$, equivalence 53 to 83 ) and intervention ( $n=58,95 \%$ CI 44 to 75$){ }^{26}$ 
Table 3 Summary of Patient Safety Outcomes in Remote Triage Studies

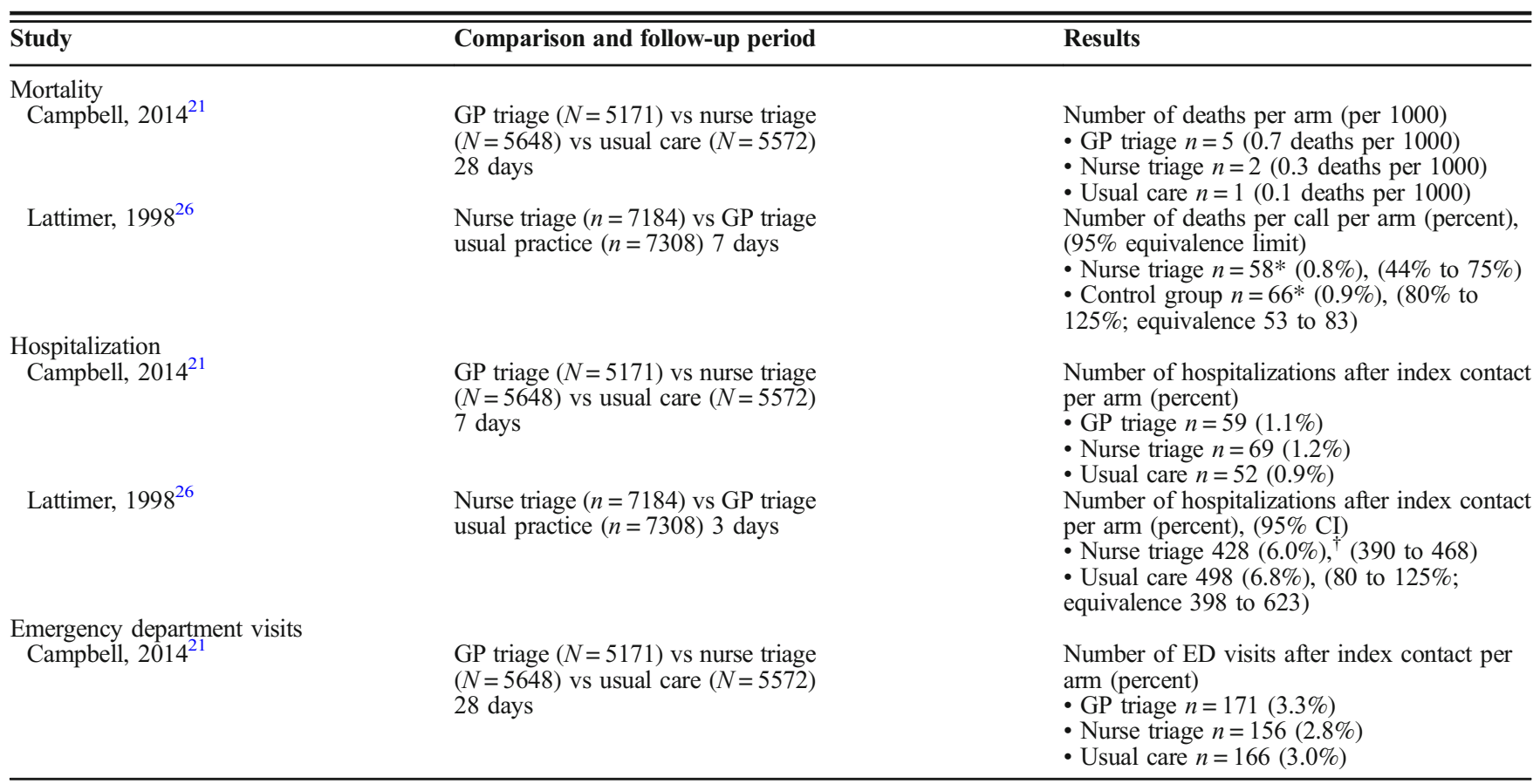

${ }^{\dagger}$ Percentages calculated based on the total number of calls

Hospitalizations. Within 7 days, approximately $1 \%$ of patients in the three-arm RCT had at least one hospital admission: GP triage $(n=59,1.1 \%)$, nurse triage $(n=69$, $1.3 \%)$, and usual care ( $n=52,0.9 \%$, Fig. 2). Compared with usual care, telephone triage was associated with a nonsignificant trend toward increased admissions with GPs (OR $1.17,95 \%$ CI 0.75 to 1.85 ) or nurses (OR $1.31,95 \%$ CI 0.83 to 2.07 ), with no significant difference between nurse versus GP triage (OR 1.12, 95\% CI 0.73 to 1.72). ${ }^{21}$ The equivalence trial comparing GP with nurse telephone triage found no differences in hospitalizations at $24 \mathrm{~h}$ (433, equivalence 346 to 541 vs $375 ; 95 \%$ CI 339 to 414 ) or 3 days (498, equivalence 398 to 623 vs 428 ; $95 \%$ CI 390 to 468$).{ }^{26}$

ED Visits. Over 28 days, the three-arm RCT found approximately $3 \%$ of patients had at least one ED visit (GP triage $n=$ $171(3.3 \%)$, nurse triage $n=156(2.9 \%)$, or usual care $n=166$ (3.0\%), Fig. 2). There were similar nonsignificant findings comparing nurse (OR 1.09, 95\% CI 0.80 to 1.49 ) or GP triage (OR $1.18,95 \%$ CI 0.87 to 1.61 ) to usual care, and nurse triage to GP triage (OR $0.9295 \%$ CI 0.67 to 1.26 ). ${ }^{21}$

\section{Quality of Evidence}

Across all five randomized studies, three were rated low $\mathrm{ROB},{ }^{23,}{ }^{25},{ }^{26}$ one unclear ROB, ${ }^{21}$ and one high $\mathrm{ROB} .{ }^{27}$ One nonrandomized design was rated low $\mathrm{ROB},{ }^{24}$ one unclear $\mathrm{ROB},{ }^{22}$ and one high ROB ${ }^{28}$ Results are further summarized in Appendix Figs. 2-4.

\section{DISCUSSION}

Remote acute clinical triage centers are an increasingly prevalent feature of health care delivery, particularly among large organizations, and can vary by contact modalities and staffing models. The promise of these systems is to expand access while decreasing barriers related to distance, cost, and provider and patient time. ${ }^{17}$ Increasing access to timely PC advice may also avert costly ED and urgent care visits. ${ }^{29}$ Despite technological advances, there remain many unanswered questions about the impact of remote triage on key health care outcomes. We sought to evaluate the effectiveness of remote triage innovations and explore differences by triage mode. Unfortunately, the identified studies were too heterogeneous to conduct metaanalyses. Further, no study meeting eligibility criteria investigated delivery modalities other than in-person and telephone, making it impossible to address the impact of different modalities, such as video.

Most included studies did not demonstrate a decrease in PC or ED utilization; however, the current evidence on subsequent utilization after use of remote telephone triage services is limited and of marginal quality. Only one high ROB study found a significant decrease in subsequent PC utilization when comparing a national telephone triage system to a local telephone system, ${ }^{28}$ and no study found a decrease in ED utilization. Instead, four studies reported significant increases in utilization. ${ }^{21,22,24,25}$

One possible goal for remote triage centers is providing case resolution at initial contact. In this review, two studies showed local, practice-based phone triage services resulted in a greater 


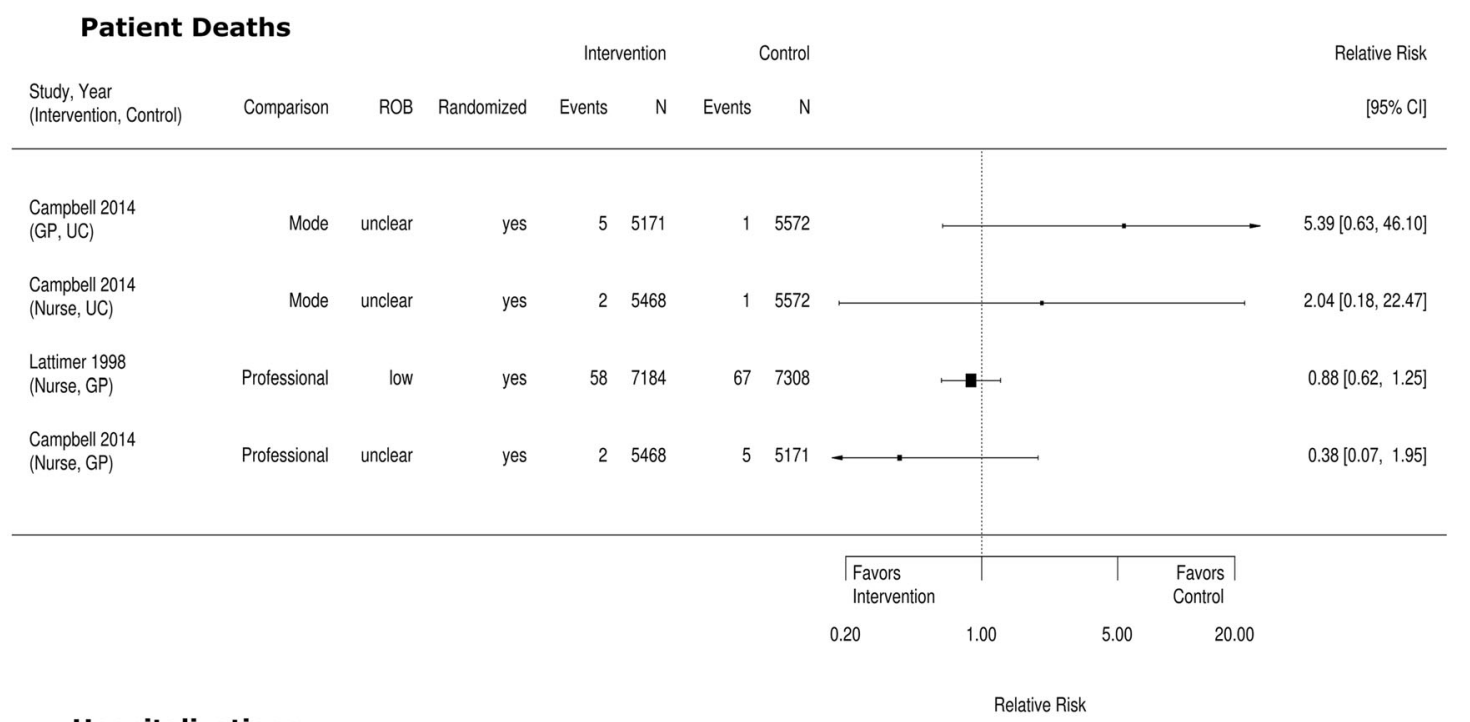

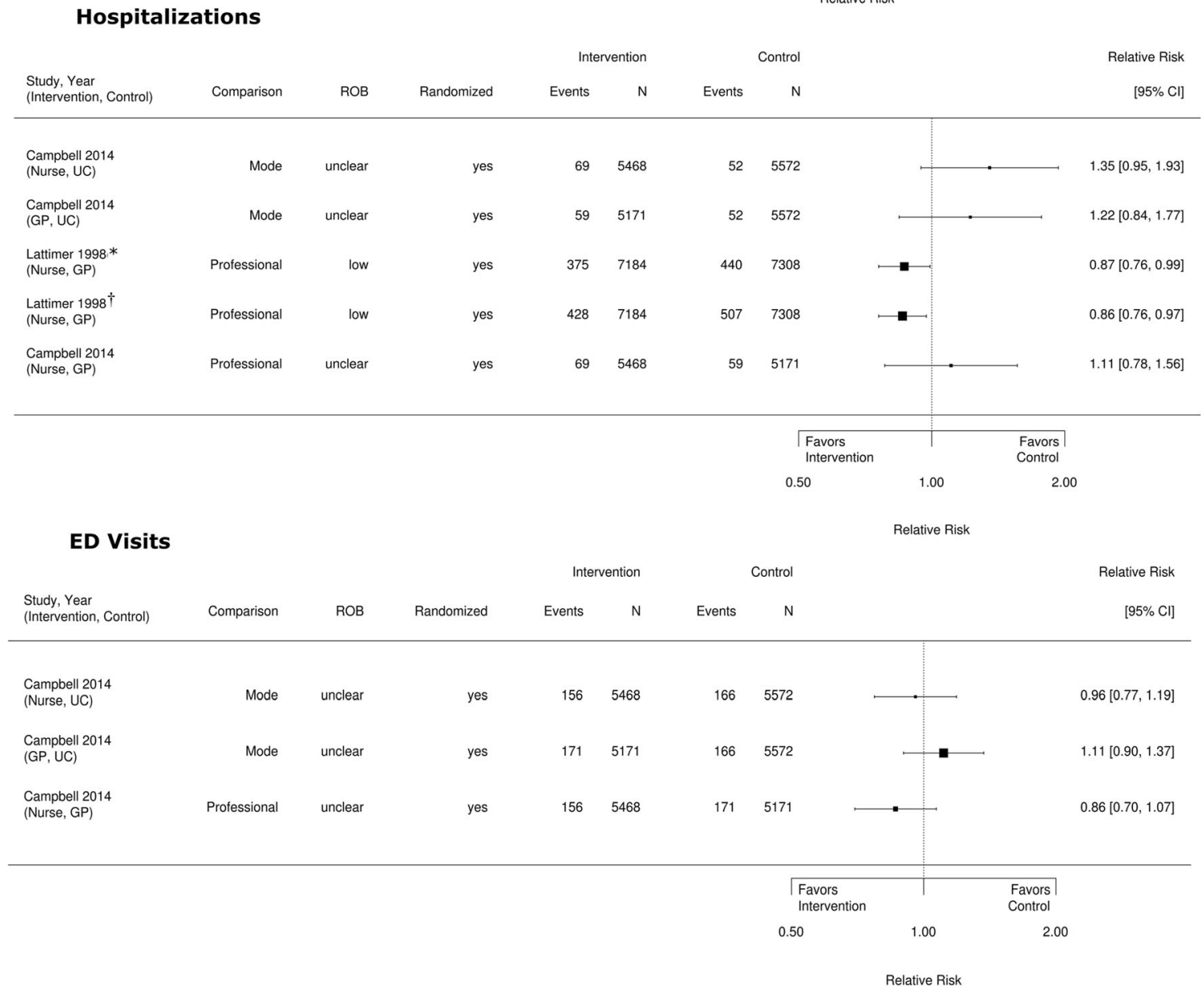

Figure 2 Effects of remote triage on patient safety outcomes. *Number of hospital admissions within 24 h of index contact. ${ }^{\dagger}$ Number of hospital admissions within 3 days of index contact. $\mathbf{C I}=$ confidence interval; $\mathbf{G P}=$ general practitioner; $\mathrm{ROB}=$ risk of bias; $\mathrm{UC}=$ usual care.

percentage of case resolution compared with regional/national systems. $^{23,} 27$ Thus, remote triage systems at higher organizational levels may need to prioritize determining appropriate triage destinations over case resolution. Such remote triage systems covering larger areas should consider organizational structures to enhance integration with the practices they serve. For instance, services could be designed with different teams of call handlers for each practice or small group of practices, with access to full patient records. No clear patterns emerged about the effects of remote triage on patient safety, although only two studies ${ }^{21,26}$ addressed safety outcomes.

Most prior reviews of telephone triage have included primarily observational studies, ${ }^{17,} 30,31$ with only an older Cochrane review similarly limiting studies to those meeting 
comparative study designs included in the EPOC criteria. Like our review, no other study found sufficient homogeneity to allow meta-analyses. ${ }^{32}$ Across the literature, the most consistent finding is that telephone triage does not decrease ED visits, ${ }^{32}$ similar to this report. There is evidence as noted in the original Cochrane review that telephone triage may reduce GP workload in the near-term, although later studies have suggested visits may merely be deferred rather than prevented. $^{30,32}$ In contrast to previous studies, we report no reduction of $\mathrm{PC}$ utilization in patients experiencing remote triage and found four studies identifying increased rates of PC use. Only three of our eight studies also were included in the 2004 Cochrane review, likely accounting for the differences in utilization results in our current work.

As multimodal contact options are important when designing a modern remote triage system, entering triage systems by means other than telephone would be important to study and understand. In particular, SMS, video calls, and chat features may be preferred means of contact for many patients, underscoring the need for more study of how triage professionals receive and process requests. Unfortunately, we were not able to identify evidence regarding multimodal contact centers.

Our review has a number of strengths, including a protocoldriven design, a comprehensive search, inclusion of EPOC designs to assess interventions, and careful quality assessment. Both our review and the literature, however, have limitations. Our review was limited to English-language publications, although the likelihood of identifying relevant data unavailable from these sources is low. The number of comparative EPOC studies was small, and most had design limitations. Given this small number, formal statistical analysis to detect publication bias was not performed. Additionally, many of the studies available had significant potential biases, with $50 \%$ of studies assessed as unclear or high ROB. Further, interventions were often described incompletely for key details such as triage protocols. Finally, remote clinical triage is a complex intervention, and identified studies were too heterogeneous to perform meta-analysis. We therefore clustered our narrative synthesis by comparison type, focusing first on higher quality designs.

\section{CONCLUSIONS}

The US health care system faces several challenges limiting access to PC, pushing some patients to seek care in other settings. Our review found limited evidence to support remote triage as a viable approach to reducing the burden on PC or ED utilization. However, remote triage by telephone can produce a high rate of call resolution and did not show evidence of patient harm in limited studies assessing safety outcomes. Further study is needed to realize the promise of remote triage in optimizing health care outcomes.

Corresponding Author: Joel C. Boggan, MD, MPH; Hospital Medicine Team (111M), Durham Veterans Affairs Health Care System, 508 Fulton Street, Durham, NC 27705, USA (e-mail: Joel.boggan@va.gov).
Authors' Contribution The authors gratefully acknowledge Chad Kessler for his help with topic scoping, Eric Monson for his help with data visualization, Belinda Ear for help with project administration, and Liz Wing for editorial assistance. Additionally, we would like to thank the following key stakeholders and technical expert panel members for their feedback during the development and execution of this project: Jennifer MacDonald, Elizabeth Yano, Peter Kaboli, and Danielle Rose.

Funding Information This project was funded by the Department of Veterans Affairs, Veterans Health Administration, Office of Research and Development, Quality Enhancement Research Initiative (ESP 09010). This work was also supported by the Durham Center of Innovation to Accelerate Discovery and Practice Transformation (ADAPT) (CIN 13-410) at the Durham VA Health Care System. The views expressed are those of the authors and do not reflect the official views or policy of the Department of Defense or its Components. Dr. Goldstein's effort is supported by VA HSR\&D CDA award no. 13-263. Dr. Van Voorhees's effort is supported by VA Rehabilitation Research and Development CDA (1K2RXO01298). Dr. Whited is supported by VA HSR\&D Award SDR 16-192. Dr. Lewinski is supported by a VA OAA HSR\&D PhD Fellowship TPH 21-00O.

\section{Compliance with Ethical Standards:}

Conflict of Interest: The authors declare that they do not have a conflict of interest.

\section{REFERENCES}

1. Population Reference Bureau. Fact Sheet: Aging in the United States. Report. Available at: https://www.prb.org/aging-unitedstates-factsheet/. Accessed 6 Dec 2018.

2. Ailes EC, Gilboa SM, Honein MA, Oster ME. Estimated number of infants detected and missed by critical congenital heart defect screening. Pediatrics. 2015;135(6):1000-8.

3. Centers for Disease Control and Prevention (CDC). National Center for Chronic Disease Prevention and Health Promotion. Multiple Chronic Conditions. Available at: https://www.cdc.gov/chronicdisease/about/ multiple-chronic.htm. Accessed 6 Dec 2018.

4. Agency for Healthcare Research and Quality. The Distribution of the U.S. Primary Care Workforce. Available at: https://www.ahrq.gov/ research/findings/factsheets/primary/pcwork3/index.html. Accessed 6 Dec 2018.

5. Bodenheimer T, Pham HH. Primary care: current problems and proposed solutions. Health Aff (Millwood). 2010;29(5):799-805.

6. Kullgren JT, McLaughlin CG, Mitra N, Armstrong K. Nonfinancial barriers and access to care for U.S. adults. Health Serv Res. 2012;47(1 Pt 2):462-85.

7. Douthit N, Kiv S, Dwolatzky T, Biswas S. Exposing some important barriers to health care access in the rural USA. Public Health. 2015;129(6):611-20.

8. Pitts SR, Carrier ER, Rich EC, Kellermann AL. Where Americans get acute care: increasingly, it's not at their doctor's office. Health Aff (Millwood). 2010;29(9):1620-9.

9. Gindi RM, Black LI, Cohen RA. Reasons for Emergency Room Use Among U.S. Adults Aged 18-64: National Health Interview Survey, 2013 and 2014. Natl Health Stat Report. 2016(90):1-16.

10. O'Malley AS. After-hours access to primary care practices linked with lower emergency department use and less unmet medical need. Health Affairs. 2013;32(1): 175-183.

11. van Galen LS, Car J. Telephone consultations. BMJ. 2018;360k1047.

12. Mechanic OJ, Kimball AB. Telehealth Systems. StatPearls. Treasure Island (FL); 2018.

13. Shih J, Portnoy J. Tips for Seeing Patients via Telemedicine. Curr Allergy Asthma Rep. 2018;18(10):50.

14. Saliba V, Legido-Quigley H, Hallik R, Aaviksoo A, Car J, McKee M. Telemedicine across borders: a systematic review of factors that hinder or support implementation. Int J Med Inform. 2012;81(12):793-809. 
15. Bunn F, Byrne G, Kendall S. Telephone consultation and triage: effects on health care use and patient satisfaction. Cochrane Database Syst Rev. 2004(4):Cd004180.

16. Ismail SA, Gibbons DC, Gnani S. Reducing inappropriate accident and emergency department attendances: a systematic review of primary care service interventions. Br J Gen Pract. 2013;63(617):e813-20.

17. Lake R, Georgiou A, Li J, et al. The quality, safety and governance of telephone triage and advice services - an overview of evidence from systematic reviews. BMC Health Serv Res. 2017;17(1):614.

18. Moher D, Liberati A, Tetzlaff J, Altman DG. Preferred reporting items for systematic reviews and meta-analyses: the PRISMA statement. PLoS Med. 2009;6(7):e1000097.

19. Evidence Partners Inc. DistillerAI website. Available at: https://www. evidencepartners.com/distiller-ai/. Accessed 12 Oct 2018.

20. Cochrane Effective Practice and Organisation of Care (EPOC). Suggested risk of bias criteria for EPOC reviews. EPOC Resources for review authors. 2017. Available at: http://epoc.cochrane.org/resources/epocresources-review-authors Accessed 17 May 2018.

21. Campbell JL, Fletcher E, Britten N, et al. Telephone triage for management of same-day consultation requests in general practice (the ESTEEM trial): a cluster-randomised controlled trial and costconsequence analysis. Lancet. 2014;384(9957):1859-1868.

22. Turner J, O'Cathain A, Knowles E, Nicholl J. Impact of the urgent care telephone service NHS 111 pilot sites: a controlled before and after study. BMJ Open. 2013;3(11):e003451.

23. Richards DA, Godfrey L, Tawfik J, et al. NHS Direct versus general practice based triage for same day appointments in primary care: cluster randomised controlled trial. BMJ. 2004;329(7469):774

24. Richards DA, Meakins J, Tawfik J, et al. Nurse telephone triage for same day appointments in general practice: multiple interrupted time series trial of effect on workload and costs. BMJ. 2002;325(7374):1214.

25. McKinstry B, Walker J, Campbell C, Heaney D, Wyke S. Telephone consultations to manage requests for same-day appointments: a randomised controlled trial in two practices. Br $\mathrm{J}$ Gen Pract. 2002;52(477):306-10

26. Lattimer V, George S, Thompson F, et al. Safety and effectiveness of nurse telephone consultation in out of hours primary care: randomised controlled trial. The South Wiltshire Out of Hours Project (SWOOP) Group. BMJ. 1998;317(7165):1054-9.

27. Cragg DK, McKinley RK, Roland MO, et al. Comparison of out hours care provided by patients' own general practitioners and commercial deputising services: a randomised controlled trial. I: The process of care. BMJ. 1997;314(7075):187-9.

28. Munro J, Nicholl J, O'Cathain A, Knowles E. Impact of NHS Direct on demand for immediate care: Observational study. BMJ. 2000;321(7254):150-153.

29. Friedman BW, Mulvey L, Davitt M, et al. Predicting 7-day and 3-month functional outcomes after an ED visit for acute nontraumatic low back pain. Am J Emerg Med. 2012;30(9): 1852-1859.

30. Downes MJ, Mervin MC, Byrnes JM, Scuffham PA. Telephone consultations for general practice: a systematic review. Syst Rev. 2017;6(1):128.

31. Blank L, Coster J, O'Cathain A, et al. The appropriateness of, and compliance with, telephone triage decisions: a systematic review and narrative synthesis. J Adv Nurs. 2012;68(12):2610-21.

32. Bunn F, Byrne G, Kendall S. The effects of telephone consultation and triage on healthcare use and patient satisfaction: a systematic review. $\mathrm{Br}$ J Gen Pract. 2005;55(521):956-61.

Publisher's Note Springer Nature remains neutral with regard to jurisdictional claims in published maps and institutional affiliations. 